\title{
Modeling and Forecasting Gambia's Inflation Rates
}

\author{
Sanna Manjang $^{1}$, Abdou Ka Diongue ${ }^{2} \&$ Leo Odongo $^{3}$ \\ ${ }^{1}$ Pan African University (PAUISTI), Institute for Basic Sciences Technology and Innovation, Kenya \\ ${ }^{2}$ University Gaston Berger, Senegal \\ ${ }^{3}$ Kenyatta University, Kenya \\ Correspondence: Sanna Manjang, African University (PAUISTI), Institute for Basic Sciences Technology and \\ Innovation, Kenya. Tel: 220-372-6639 or 254-71-708-1063. E-mail: sannamanjang@gmail.com
}

Received: July 25, 2014

Accepted: August 9, 2014

Online Published: September 25, 2014

doi:10.5539/ijef.v6n10p129

URL: http://dx.doi.org/10.5539/ijef.v6n10p129

\begin{abstract}
In this paper, we examine the most appropriate method for modeling and forecasting Gambia's inflation rates. We investigate the statistical properties of the inflation data and specify two models namely seasonal autoregressive integrated moving average (SARIMA) and k-factor Gegenbauer Autoregressive Moving Average (k-factor GARMA). The first model seasonal $\operatorname{ARIMA}(1,1,1)(0,0,1)_{12}$ was selected using the H-K Algorithm developed by Hyndman and Khandakar (2008) and 3-factor GARMA from both the spectral density graph and further analysis of the residuals from the 3-factor Gegenbauer model. The in-sample characteristics such as the Akaike Criterion and Schwarz Criterion following estimation using the first data set show that the $\operatorname{ARIMA}(1,1,1)(0,0,1)_{12}$ outperforms the 3-factor GARM A model. However, the second data set that was preserved and used for out-of-sample forecasting suggest that the 3 -factor GARMA model outperforms the seasonal $\operatorname{ARIMA}(1,1,1)(0,0$, 1) 12 model in out-of -sample forecasting. Our results indicated that inflation in Gambia is stationary with long-memory behavior at three distinct frequencies. We also found that the k-factor GARMA outperforms the seasonal ARIMA in out-sample forecasting which may be ascribed to the forecast horizon been large and series strongly long-range dependent.
\end{abstract}

Keywords: SARIMA, k-factor GARMA, inflation, fractional integration, long memory

\section{Introduction}

Inflation as defined by Webster (2000) is the persistent increase in the level of consumer prices or a persistent decline in the purchasing power of money. Inflation causes global concern because it can distort economic patterns when not anticipated. Inflation as described by Aidoo (2010) can cause uncertainty about the future price, interest rate, and exchange rate etc which as a result might increase the risk among potential traders and partners of a country. Inflation in The Gambia exhibit evidence of cyclical persistence justifying the use of a seasonal model such as SARIMA (seasonal autoregressive integrated moving average) which is an extension of the ARIMA model when the series contains both seasonal and non-seasonal behavior and a long memory model such as k-factor Gegenbauer autoregressive moving average (k-factor GARMA) in modeling it.

A stationary process is said to be long memory if it exhibits a slowly decaying autocorrelation function (ACF), denoted $\rho(n)$, approximated as follows: $\rho(n) \approx c_{p}(n) n^{2 d-1}$, as $n$ tends to infinity, where $c_{p}(n)$ is a slowly varying function at infinity and $d$ is the long memory parameter such that $0<d<1 / 2$, and therefore the infinite sum $\Sigma|\rho(n)|$ diverges. In an equivalent way, in terms of spectral analysis, a stationary process is said to be long memory if for some frequency $\lambda \in[0, \pi]$ the spectral density becomes unbounded (Woodward et al., 2011). Forecasters need to take into account long-range dependence in modeling time series to obtain accurate results. In many economic and financial applications, time series often possess persistent cycles, especially when dealing with daily or monthly frequencies. To take into account this periodic and persistent behavior long memory models have been proposed which makes it possible to integrate a certain type of nonstationarity in modeling and therefore avoids a differentiation of the series which strongly reduces the available information set. Long-range dependence has been studied extensively and evidence of it can be found in many areas of applied statistics. For instance, the pioneer work of Hurst (1951) stems from problems dealing with hydrology, and later many authors analyzed river flows through long memory processes, see for instance Noakes et al. (1998) or Ooms and Franses (1998). More recently, researchers founded evidence of persistence in 
telecommunication data (Taqqu et al., 1997) or in urban transport data (Ferrara \& Guegan, 1999). However, most long memory applications concern financial time series such as stock market prices, exchange rates, inflation, etc.

\section{Literature Review}

Empirical researches have been carried out in the area of forecasting using Autoregressive Integrated Moving Average (ARIMA) models popularised by Box and Jenkins (1976). Junttila (2001), applied the Box and Jenkins (1976) approach to model and forecast Finnish inflation. Pufnik and Kunovac (2006) applied a similar approach to forecast short term inflation in Croatia. Alnaa and Ferdinand (2011) used ARIMA approach to predict inflation in Ghana. In their study, they used monthly data from June, 2000 to December, 2010 and found that ARIMA $(6,1,6)$ is best for forecasting inflation in Ghana. An extended version of the Seasonal ARIMA, known as the Driftless Extended Seasonal ARIMA (DESARIMA) was introduced in a study by Pincheira and Medel (2012) to forecast inflation across 12 countries. Also, Barros and Gil-Alana (2012) employed a fractional approach (Autoregressive Fractionally Integrated Moving Average) to forecast inflation in Angola. Adjepong et al. (2013) considered the most appropriate short-term forecasting method for Ghana's inflation: Seasonal ARIMA vs. Holt-Winters. They concluded by proposing the Seasonal-ARIMA process as the most appropriate short-term forecasting method for Ghana's inflation. Recently Long-memory models have then become increasingly popular (Hassler and Wolters, 1995). (see, e.g., Chung \& Baillie, 1993; Franses \& Ooms, 1997). Much of the evidence supports the view that inflation is fractionally integrated with a differencing parameter that is significantly different from zero or unity (Sutcliffe, 1994). For instance, using US monthly data, Backus and Zin (1993) found a fractional degree of integration. They argued that aggregation across agents with heterogeneous beliefs results in long memory in the inflation process. Hasser (1993) and Delgado and Robinson (1994) provided strong evidence of long memory in the Swiss and Spanish inflation rates respectively. A new class of Fractionally Integrated Generalized AutoRegressive Conditionally Heteroskedastic (FIGARCH) processes was introduced by Baillie et al. (1996). Empirical evidence of long memory has also been found in monthly river flows (Ooms \& Franses, 1998), stock market prices (Cheung \& Lai, 1995), (Barkoulas \& Baum, 1996), Willinger et al. (1999) or exchange rates (Cheung, 1993), Bisaglia and Guégan (1998), Velasco (1999). Caporale and Gil-Alana (2011) modeled European inflation rates using Multi-Factor Gegenbauer Processes. Their findings show that inflation in France and Italy is nonstationary, but in the former country this applies to both the long-run and the seasonal frequencies, whilst for the latter the nonstationarity concerns exclusively the long-run or zero frequency, and the contribution of the long-range dependence in the seasonal structure is relatively small. For the UK, inflation seems to be stationary, though with a large component of long-memory behaviour, especially at the zero frequency. In the present study we model Gambia inflation rates which to the best of our knowledge have not been done before. We specify a seasonal autoregressive integrated moving average (SARIMA) model and k-factor Gegenbauer Autoregressive Moving Average (k-factor GARMA) model for the Gambia inflation rates and compare their in-sample characteristics and out-sample forecasting performances. Our results indicated that inflation in Gambia is stationary with long-memory behavior at three distinct frequencies. We also found that the k-factor GARMA outperforms the seasonal ARIMA in out-sample forecasting which may be ascribed to the forecast horizon been large and series strongly long-range dependent.

The outline of this paper is as follows: section III describes the inflation data from the Central Bank of The Gambia. In section IV we present the two models namely seasonal autoregressive integrated moving average (SARIMA) model and k-factor Gegenbauer Autoregressive Moving Average (k-factor GARMA) model, section $\mathrm{V}$ deals with applications, and section VI gives a summary of our findings.

\section{Data Presentation}

The data was obtained from the Central Bank of the Gambia spanning the period January 1987 to June 2013 and is measured in percentages based on the consumer price index (CPI) of The Gambia. Figure 1 shows the graphical representations of realizations, distribution function, periodogram and the autocorrelation function. The spectral density is unbounded at the low frequencies and the autocorrelation function decay very slowly which suggest that the inflation series seems to be long memory process with fractional integration behavior. The periodogram exhibits three distinct spikes at the low frequencies and smaller peaks at other seasonal frequencies which are all indications that the inflation process in Gambia is possibly fractionally integrated with $0<d<1, i=1, \ldots, k$ where $\mathrm{k}$ is a finite integer indicating the number of seasonal structures. Patterns of seasonality are evident in the plot of the realizations and the autocorrelation function. 
Realization

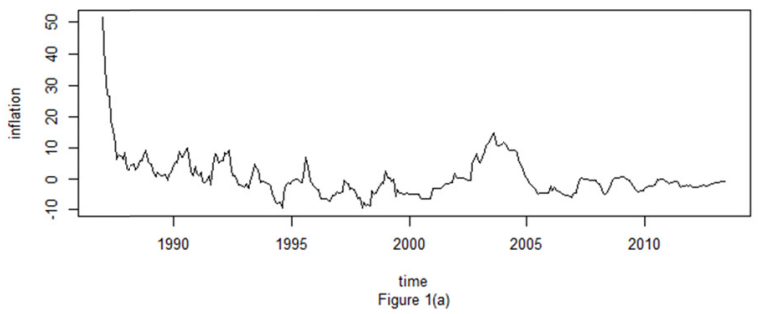

Residual Spectrum with long memory in the three seasonal frequencies

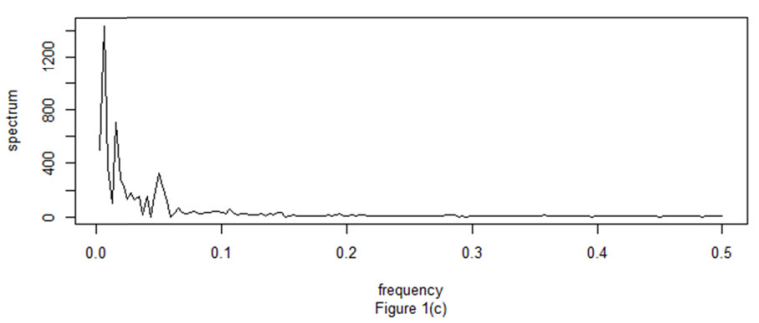

frequency distribution of inflation (Non-gaussian)

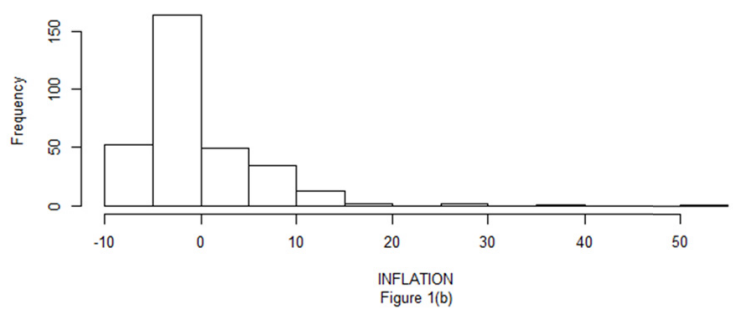

ACF OF Gambian monthly inflation rates with clear seasonal patterns

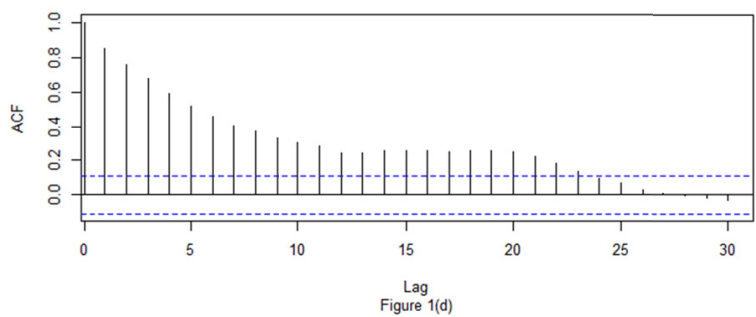

Figure 1. Realization, frequency distribution, periodogram and autocorrelations of inflation rates

Moreover, graphical inspection of the inflation series from Figure 1 suggests that this series might not be stationary as it exhibits certain amount of volatility with a trend cycle. In the unit root tests that follow we include both constant and trend. Using the HEGY test for seasonal roots (Hylleberg et al., 1990), with results presented in Table 1 we can conclude that the null hypothesis of a unit root at zero frequency cannot be rejected. In addition, both the ADF (Dickey \& Fuller, 1979) and KPSS (Kwiatkowski et al., 1992) tests (see Table 2) give the same result as the HEGY. However, the presence of seasonal unit roots is rejected at all frequencies at the 5\%, significance level.

Table 1. HEGY Seasonal Unit Root plus trend for inflation rates

\begin{tabular}{lccc}
\hline Auxillary Regression & Seasonal Frequency & Critical values & Test statistic \\
\hline t-test: $\pi_{1}=0$ & 0 & -3.37 & $-0.7762^{*}$ \\
t-test : $\pi_{2}=0$ & $\pi$ & -1.94 & $-6.1885^{*}$ \\
F-test : $\pi_{3}=\pi_{4}=0$ & $\frac{\pi}{2}$ & 3.05 & $53.6823^{*}$ \\
F-test: $\pi_{5}=\pi_{6}=0$ & $\frac{2 \pi}{3}$ & 3.05 & $59.1069^{*}$ \\
F-test: $\pi_{7}=\pi_{8}=0$ & $\frac{\pi}{3}$ & 3.08 & \\
test: $\pi_{9}=\pi_{10}=0$ & $\frac{5 \pi}{6}$ & 3.08 & $45.1287^{*}$ \\
test: $\pi_{11}=\pi_{12}=0$ & $\frac{\pi}{6}$ & 3.09 & $67.8777^{*}$ \\
test: $\pi_{1}=\ldots \pi_{12}=0$ & & & $33.2156^{*}$ \\
test: $\pi_{2}=\ldots \pi_{12}=0$ & & 2.30 & $61.5118^{*}$ \\
\hline
\end{tabular}

Note. *Seasonal unit root is rejected at the $5 \%$ significance level.

Table 2. Unit root test for inflation in level form

\begin{tabular}{lllll}
\hline & \multicolumn{1}{c}{ Constant } & & \multicolumn{2}{c}{ Constant+Trend } \\
Test type & Critical Value & Test Statistic & Critical Value & Test Statistic \\
\hline ADF & -2.878 & -2.601 & -3.428 & -2.555 \\
KPSS & 0.463 & 0.9014 & 0.148 & 0.3727 \\
\hline
\end{tabular}

Note. Test of the null hypothesis of a unit root with test statistic and critical values. 


\section{Model Presentation}

\subsection{Seasonal ARIMA Model}

The extension of ARIMA model to the SARIMA model comes in when the series contains both seasonal and non- seasonal behavior. This behavior of the series makes the ARIMA model inefficient to be applied to the series. This is because it may not be able to capture the behavior along the seasonal part of the series and therefore mislead to a wrong order selection for non-seasonal component.

If $d$ and $D$ are nonnegative integers, the $\{x\}$ is a seasonal $A R I M A(p, d, q)(P, D, Q)_{S}$ process with period $s$ if the differenced series $y_{t}=(1-B)^{d}(1-B)^{D} x_{t}$ is a casual ARMA process defined by:

$$
\phi_{p}(B) \Phi_{p}(B)(1-B)^{d}\left(1-B^{s}\right)^{D} X_{t}=\theta_{q}(B) \Theta_{Q}\left(B^{s}\right) \boldsymbol{\varepsilon}_{t}, \boldsymbol{\varepsilon}_{t}^{\sim} W N\left(0, \sigma^{2}\right)
$$

where

$$
\begin{array}{r}
\phi_{p}(x)=1-\phi_{1}(x)-\ldots-\phi_{p}(x), \Phi_{p}(x)=1-\Phi_{1}(x)-\ldots-\Phi_{p}(x) \\
\theta_{q}(x)=1+\theta_{1}(x)+\ldots+\theta_{q}(x) \text { and } \Theta_{Q}(x)=1+\Theta_{1}(x)+\ldots+\Theta_{Q}(x)
\end{array}
$$

Remark. Note that the process $y_{t}$ is casual if and only if $\phi(x) \neq 0$ and $\Phi(x)=0$ for $|x| \leq 1$. In applications $d$ is rarely more than one and $P$ and $Q$ are typically less than three (Brockwell \& Davis, 2002).

To select the best SARIMA model we use an algorithm developed by Hyndman and Khandakar (2008) called the HK-algorith.

\subsection{The k-factor GARMA Model}

The k-factor Gegenbauer process $\left(X_{t}\right)_{t} \in_{Z}$ is defined by the following quation:

$$
\prod_{j=1}^{k}\left(I-2 v_{j} B+B^{2}\right)^{d_{j}}\left(X_{t}-\mu\right)=\varepsilon_{t}
$$

where $k$ is a finite integer indicating the maximum number of seasonal structures, where $\left|v_{j}\right| \leq 1$ for $j=1, \ldots, k$, where $d_{j}$ 's are fractional values for $j=1, \ldots, k$, where $\mu$ is the mean of the process and where $\left(\varepsilon_{t}\right)_{t} \in Z$ is covariance stationary with mean zero and variance $\sigma_{\varepsilon}^{2}$ (Gray et al., 1989).

The k-factor GARMA model is defined by the following equation:

$$
\phi(B) \prod_{j=1}^{k}\left(I-2 v_{j} B+B^{2}\right)^{d_{j}}\left(X_{t}-\mu\right)=\boldsymbol{\theta}(B) \boldsymbol{\varepsilon}_{t}
$$

where $0<d<1 / 2$, if $\left|v_{j}\right|<1$ or $0<d<1 / 4$ if $\left|v_{j}\right|=1$ for all $j=1, \ldots, k$.

(For stationarity and invertibility conditions refer to Gray et al. (1989)).

To estimate the parameters of the k-factor GARMA model, we use in this study the Whittle approach as in Diongue and Guegan (2008).

The first step involves estimating the long-memory parameters $d=\left(d_{1}, \ldots, d_{k}\right)$ and the $A R M A(p, q)$ parameters $\alpha=\left(\phi_{1}, \ldots \phi_{p}, \theta_{1}, \ldots, \theta_{p}\right)$ using Whittle's method.

Let $\hat{\gamma}=\left(\hat{d}_{1}, \ldots, \hat{d}_{k}, \hat{\phi}_{1}, \ldots, \hat{\phi}_{p}, \hat{\theta}_{1}, \ldots, \hat{\theta}_{q}\right)$ be the Whittle estimator based on the periodogram that involves the function

$$
L_{T}(\gamma)=\frac{1}{2 \pi} \sum_{j=1}^{T-1}\left\{\log \left[f_{X}\left(\omega_{j}, \gamma\right)\right]+\frac{I_{X}\left(\omega_{j}\right)}{f_{X}\left(\omega_{j}, \gamma\right)}\right\}
$$

Where $I_{X}\left(\omega_{j}\right)$ is the periodogram of the process $\left(X_{t}\right)_{t=1}^{T}$ and expressed as follows :

$$
I_{X}\left(\omega_{j}\right)=\frac{1}{2 \pi T}\left|\sum_{t=1}^{T} X_{t}^{2} e^{i \omega_{j} t}\right|^{2}
$$

with the frequencies $\omega_{j}$ are such that $\omega_{j}=\frac{2 \pi j}{T}, 0 \leq j \leq\left[\frac{T}{2}\right],\left[\frac{T}{2}\right]$ the integer part of $\frac{T}{2}$, and $i$ a complex number such that $i^{2}=1$. The function $f_{X}(\omega, \gamma)$ is defined by 


$$
f_{X}\left(\omega_{J}, \gamma\right)=\left|\frac{\theta\left(e^{-i \omega j}\right)}{\phi\left(e^{-i W j}\right)}\right| \prod_{i=1}^{k}\left|\left[2 \cos \left(\omega_{j}\right)-v_{l}\right]\right|^{-2 d_{1}}
$$

\section{Applications}

In this section, we use the Gambia inflation rate data for empirical modeling and test on the two models defined in the previous section.

\subsection{Model Selection}

The proper order of differencing (both seasonal and nonseasonal) has been decided from section II. i.e. $d=1, D=0$. We now determine the appropriate autoregressive orders $\mathrm{p}$ and $\mathrm{P}$ and moving average orders $\mathrm{q}$ and $\mathrm{Q}$. We will use the autocorrelation function (ACF) and partial autocorrelation (PACF) plots of the differenced series to identify the numbers of AR and/or MA terms that are needed tentatively and conclude the order selection with the HyndmanKhandakar (HK) algorithm. In Figure 2(b) the partial autocorrelation function (PACF) has a positive significant spike at lag 1 with several insignificant spikes before the seasonal lag suggesting that $\mathrm{p}$ is at least equal to 1 . In Figure 2(a) the first 3 autocorrelations are relatively significant, that is, outside the confidence band suggesting that $\mathrm{q}$ is at least 3. For the seasonal orders, since autocorrelation at the seasonal period is negative,we consider adding an SMA term to the model, in this case SMA(1). To complete the model selection we use the HyndmanKhandakar (HK) algorithm to consider the various possibilities. Using the HK-algorithm, the best model in terms of $\mathrm{AIC}, \mathrm{AIC}_{\mathrm{C}}$, and $\mathrm{BIC}$ is the $\operatorname{ARIMA}(1,1,1)(0,0,1)_{12}$ as shown in Table 3.
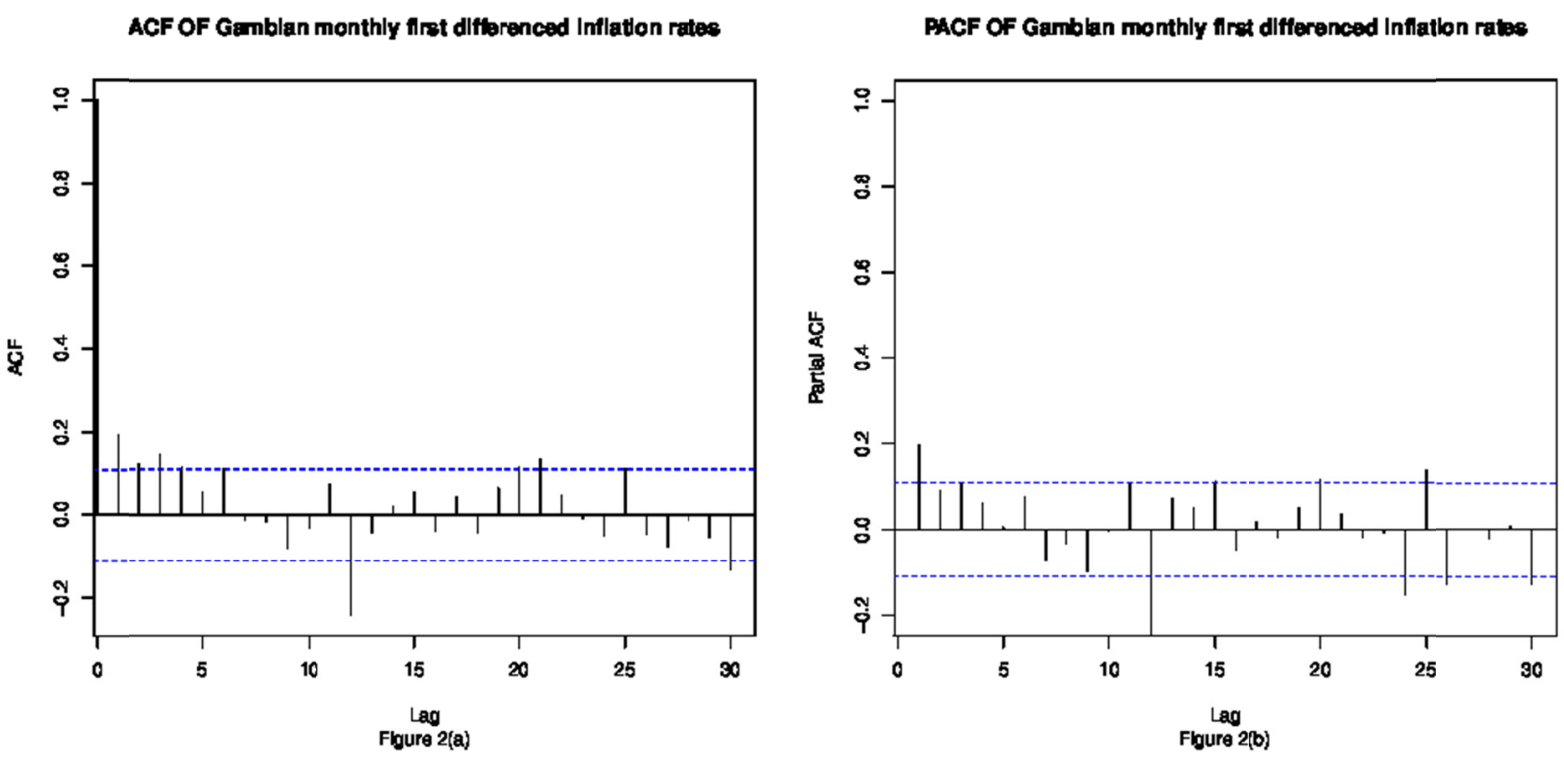

Figure 2. ACF and PACF of Gambian monthly first differenced inflation rates

Table 3. ARIMA(p, $d, q)(P, D, Q)_{12}$ chosen by each criterion (H-K Algorithm)

\begin{tabular}{|c|c|c|c|c|}
\hline Criterion & $\mathrm{AIC}$ & $\mathrm{BIC}$ & $\mathrm{AIC}_{\mathrm{c}}$ & $\mathrm{AIC}, \mathrm{BIC}, \mathrm{AIC}_{\mathrm{c}}$ \\
\hline Model Chosen & $\operatorname{ARIMA}(1,1,1)(0,0,1)_{12}$ & $\operatorname{ARIMA}(0,1,0)(0,0,1)_{12}$ & $\operatorname{ARIMA}(1,1,1)(0,0,1)_{12}$ & $\operatorname{ARIMA}(1,1,1)(0,0,1)_{12}$ \\
\hline
\end{tabular}

Table 4. AIC and BIC for the suggested SARIMA models

\begin{tabular}{llll}
\hline Model & $\mathrm{AIC}$ & $\mathrm{AIC}_{\mathrm{c}}$ & $\mathrm{BIC}_{\mathrm{c}}$ \\
\hline $\operatorname{ARIMA}(1,1,1)(0,0,1)_{12}$ & 1488 & 1488 & 1507 \\
$\operatorname{ARIMA}(1,1,1)(0,0,1)_{12}$ & 1495 & 1495 & 1503 \\
\hline
\end{tabular}


Table 5. Estimates of the $\operatorname{ARIMA}(1,1,1)(0,0,1)_{12}$

\begin{tabular}{llll}
\hline Parameter & Estimate & Standard Error & P-value \\
\hline Constant & -0.014 & 0.0175 & \\
$\Phi_{1}$ & 0.6128 & 0.0143 & $0.0000^{*}$ \\
$\theta$ & -0.5941 & 0.0386 & $0.0000^{*}$ \\
$\Theta_{1}$ & -0.5606 & 0.0383 & $0.0000^{*}$ \\
$\sigma_{\varepsilon}^{2}$ & 2.0512 & & \\
\hline
\end{tabular}

Note. $* * *$ Parameters are statistically significant.
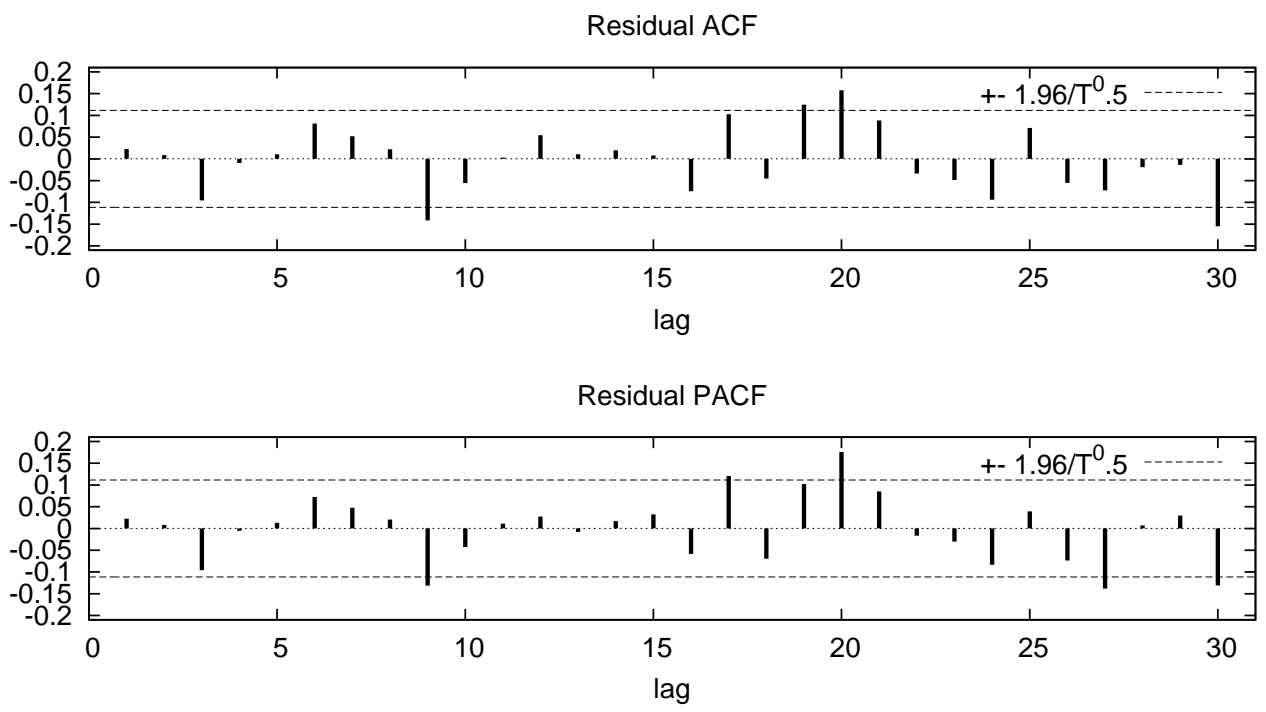

Figure 3. Residual ACF and PAC

The ACF of the residuals displayed in Figure 3 depicts that the autocorrelation of the residuals are approximately all zero, that is to say they are uncorrelated and the p-value for the Ljung-Box statistic in Table 6 clearly exceed 5\% at lag 12, indicating that there is no significant departure from white noise for the residuals. The ARCH-LM test is used to test for constant variance. From the ARCH-LM test results shown in Table 7, we fail to reject the null hypothesis of no ARCH effect (homoscedasticity) in the residuals of the selected model.

Table 6. Box-Ljung test of the null hypothesis of randomness for the residuals

\begin{tabular}{lll}
\hline Lag & Q' $^{\prime}$ & P-value \\
\hline 12 & 14.61 & 0.1024 \\
\hline
\end{tabular}

Table 7. ARCH-LM Test for homoscedasticity

Note. *Null hypothesis: no arch effect is present.

\begin{tabular}{ll}
\hline Model & P-value \\
\hline $\operatorname{ARIMA}(1,1,1)(0,0,1)_{12}$ & $0.0659^{*}$ \\
\hline
\end{tabular}

The spectral density in Figure 1 is unbounded at the low frequencies which suggest that the inflation series seems to be a long memory process with fractional integration behavior (Woodward et al., 2011). The empirical ACF of the series in Figure 1 clearly shows a strong dependence between distant observations, as well as a cyclical behavior with a pretty long period. Moreover, the spectral density of the series clearly possesses three distinct peaks with the first peak having frequency located very close, but not necessarily equal, to zero which are all distinctive features of a weakly stationary Gegenbauer process. The properties of the data suggest using a 3-factor Gegenbauer process to model inflation in Gambia.

We assume the inflation series has the following specification: 


$$
\prod_{j=1}^{3}\left(I-2 v_{j} B+B^{2}\right)^{d_{j}}\left(X_{t}-\mu\right)=\varepsilon_{t}
$$

where $\lambda_{j}=\cos ^{-1}\left(v_{j}\right), 0 \leq \lambda \leq \pi$ are called Gegenbauer frequencies.

The following results were obtained from the estimation of the long memory model, the 3-factor Gegenbauer model. The parameter estimation is done using the parametric Whittles method. The three orders of integration are $d_{1}=0.117, d_{2}=0.2744, d_{3}=0.0831$ with $L L F=1.9098$. (See Figure 4 for the residual correlogram).

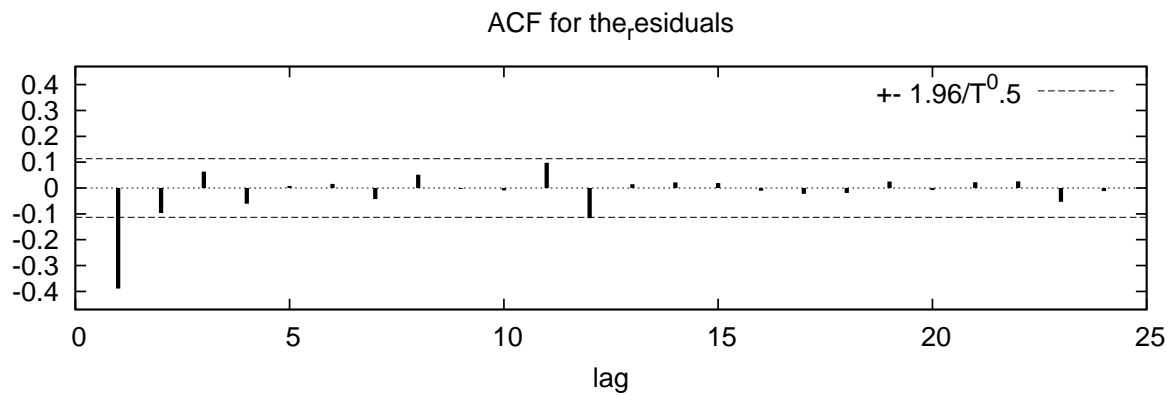

PACF for the esiduals

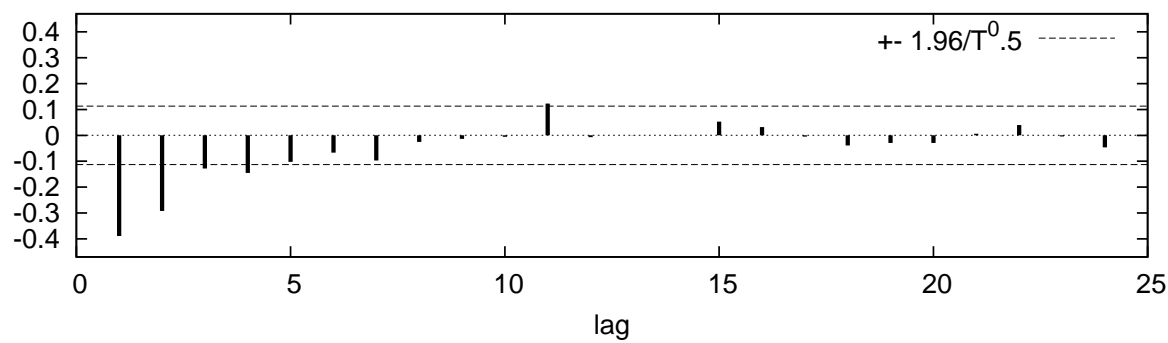

Figure 4. ACF and PACF of the 3-factor Gegenbauer model

From the autocorrelation function in Figure 4 it is obvious that the residuals are not white noise. An ARCH-LM test performed on the residuals fails to reject evidence of $\mathrm{ARCH}$ effect. We adjust various $\mathrm{ARMA}(\mathrm{p}, \mathrm{q})$ specifications on the residuals and found $\operatorname{ARMA}(0,1)$ to be most adequate with the parameter $\theta_{1}=-0.654$.

From the autocorrelation function in Figure 4 it is obvious that the residuals are not white noise.
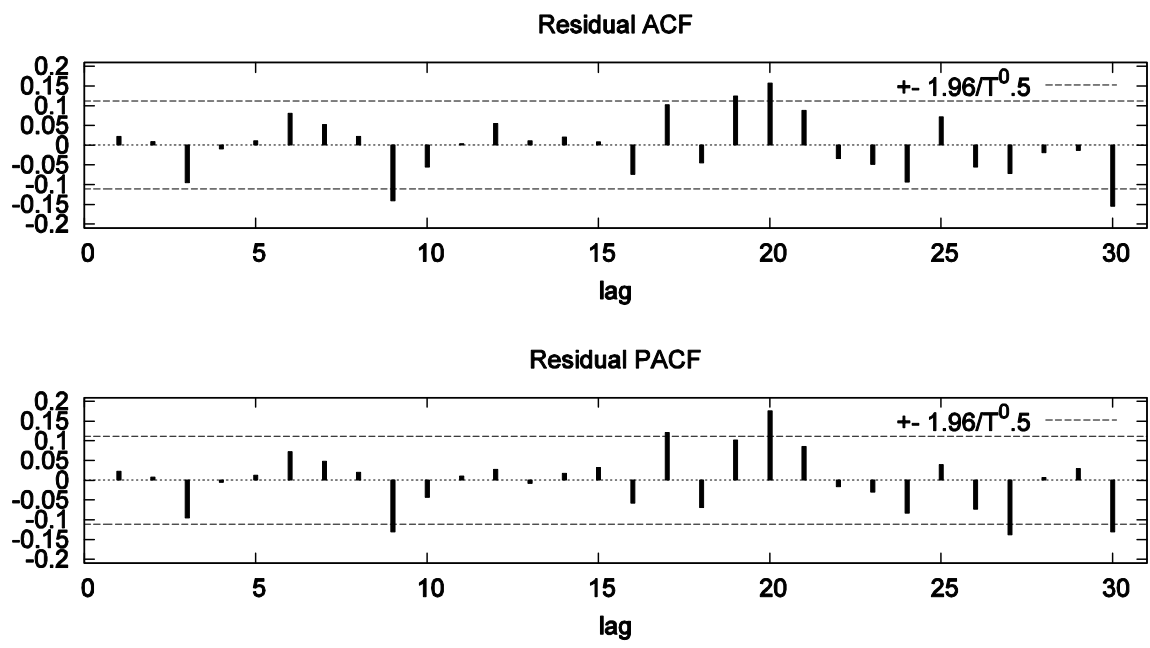

Figure 5. Behavior of ACF and PACF the distribution of the estimated residuals 
An $A R C H-L M$ test performed on the residuals fail to reject evidence of $A R C H$ effect. We adjust various $A R C H(p, q)$ specifications on the residuals and found $\operatorname{ARMA}(0,1)$ to be most adequate with the parameter $\theta_{1}=-0.654$.

The resulting k-factor GARMA model is given below.

$$
\begin{aligned}
& \left(I-2(0.9992) B+B^{2}\right)^{0.0117}\left(I-2(0.9951) B+B^{2}\right)^{0.2744}\left(I-2(0.9982) B+B^{2}\right)^{0.2744} \\
& =(1-0.654 B) \varepsilon_{t}
\end{aligned}
$$

We finally performed Box-Pierce and Ljung-Box- Pierce tests on the estimated residuals and found no evidence of autocorrelation in the model.

\subsection{Model Comparison}

When comparing the two models using the $A I C$, Schwarz Criterion, Hannan-Quinn Criterion and the standard deviation of innovation we obtain that the SARIMA model is better than the k-factor GARMA. See Table 8 for the in-sample characteristics of the two models.

Table 8. In-sample comparison

\begin{tabular}{ccc}
\hline & SARIMA model & 3-factor GARMA model \\
\hline Akaike Criterion & 1081.3 & 1651.0 \\
Schwarz Criterion & 1099.8 & 1662.1 \\
Hannan-Quinn Criterion & 1088.7 & 1655.4 \\
S.D. of innovations & 1.4601 & 3.7533 \\
\hline
\end{tabular}

To complete the study, we compare the forecasting performance of the two models using standard measures of forecast accuracy such as the following: the root-mean-squared error (RMSE), the mean-squared error (MSE), the mean absolute deviation (MAD) and Theil's U (Brockwell \& Davis, 1996).

The data set was divided into two sets, the first set for model estimation and the preserved observations for outof-sample forecasting. Table 9 shows the forecast evaluation statistics for both the $\operatorname{ARIMA}(1,1,1)(0,0,1)_{12}$ and 3-factor GARMA model. The $\operatorname{ARIMA}(1,1,1)(0,0,1)_{12}$ recorded MSE, RMSE, MAE and Theil's U of 1.3781, 1.1739, 0.8674, and 4.4847 respectively while the 3-factor GARMA recorded MSE, RMSE, MAE and Theil's $U$ of $1.2320,1.1100,0.9870$ and 0.0952 respectively. The 3-factor GARMA has the minimum values of MSE, RMSE, and Theil's $U$ compared to the seasonal $\operatorname{ARIMA}(1,1,1)(0,0,1)_{12}$ and model, hence we conclude 3-factor GARMA performs better than the seasonal ARIMA model in out-of-sample forecasting.

Table 9. Forecast results for monthly Gambia inflation time series

\begin{tabular}{ccccc}
\hline Models & MSE & RMSE & MAE & Theil's U \\
\hline Seasonal ARIMA & 1.3781 & 1.1739 & 0.8674 & 4.4847 \\
3-factor GARMA & $\mathbf{1 . 2 3 2}$ & $\mathbf{1 . 1 1}$ & 0.987 & $\mathbf{0 . 0 9 5 2}$ \\
\hline
\end{tabular}

\section{Summary and Conclusion}

In this study we investigate the statistical properties of the Gambia inflation rates and specify two models namely seasonal autoregressive integrated moving average (SARIMA) and k-factor Gegenbauer Autoregressive Moving Average (k-factor $G A R M A)$. We divided the data set into two and fit $\operatorname{ARIMA}(1,1,1)(0,0,1)_{12}$ and 3-factor GARM A to the first data set of inflation series. The first model seasonal $\operatorname{ARIMA}(1,1,1)(0,0,1)_{12}$ was selected using the H-K Algorithm developed by Hyndman and Khandakar (2008) and 3-factor GARMA from both spectral density graph and further analysis of the residuals from the 3-factor Gegenbauer model. The in-sample characteristics such as log-likelihood, Akaike Criterion, Schwarz, Hannan-Quinn, and S.D. of innovations following estimation show that the $\operatorname{ARIMA}(1,1,1)(0,0,1)_{12}$ and outperforms the 3 -factor GARMA model. The second data set (preserved) was used for out-of-sample forecasting and the forecast evaluation statistics such as the MSE, RMSE, and Theil's U suggest that the 3-factor GARMA model outperforms the seasonal ARIMA(1, 1, $1)(0,0,1)_{12}$ model in out-of-sample forecasting. Our results indicated that inflation in Gambia is stationary with long-memory behavior at three distinct frequencies. We also found that the k-factor GARMA outperforms the seasonal ARIMA in out-sample forecasting which may be ascribed to the forecast horizon been large and series strongly long-range dependent. 
It is important to note that the SARIMA methodology has certain limitations. For instance, it requires large number of observations for model identification and sometimes estimation and selection involves some form of art. Also, differencing the series in the case of nonstationarity may reduce the available information set. However, the model is parsimonious with respect to the coefficients and good in providing unconditional forecasts.

Note also that the number of peaks to be chosen in the spectral density for the Gegenbauer model remains unclear and must be investigated.

\section{Acknowledgments}

I wish to gratefully acknowledge financial support from the African Union Commission and from the Government of Kenya. I am also grateful to all the lecturers and entire staff of Pan African University especially Professor Magoma (Director) for facilitating the provision of facilities and a conducive environment for my research.

I extend my sincere gratitude to officials of Central Bank of The Gambia for providing the data necessary for this study.

\section{References}

Adjepong, M. O., Oduro, F. T., \& Oduro, S. D. (2013). Determining the better approach for short-term forecasting of Ghana's inflation: Seasonal-ARIMA vs. Holt-Winters. International Journal of Business, Humanities and Technology, 3(1).

Aidoo, E. (2010). Modeling and forecasting inflation rates in Ghana: An application of SARIMA models. Master's thesis, Dalarna University, School of Technology and Business Studies, Statistics.

Alnaa, \& Ferdinand. (2011). ARIMA approach to predicting inflation in Ghana. Journal of Economics and International Finance, 3(5), 328-336.

Backus, D., \& Zin, S. (1993). Long memory inflation uncertainty. evidence from the term structure of interest rates. Money, Credit and Banking, 25, 681-700. http://dx.doi.org/10.2307/2077735

Baillie, R. T., Bolerslev, T., \& Mikkelsen, H. O. (1996). Fractionally integrated generalized autoregressive conditional heteroskedasticity. Journal of Econometrics, http://dx.doi.org/10.1016/S0304-4076(95)01749-6

Barkoulas, J. T., \& Baum, C. F. (1996). Long term dependence in stock returns. Economics Letters, 53(3), $253-59$. http://dx.doi.org/10.1016/S0165-1765(96)00935-4

Barros, \& Gil-Alana. (2012). Inflation forecasting in Angola: A fractional approach. Working Paper 103, Instituto Superior de Economia e Gestã.

Bisaglia, L., \& Guégan, D. (1998). A comparison of techniques of estimation in long-memory processes: Application to intra-day. Computational Statistics and Data Analysis, 27, 61-81. http://dx.doi.org/10.1016/S0167-9473(97)00045-5

Box, G., \& Jenkins, G. (1976). Time Series Analysis: Forecasting and Control. Holden-Day, San Francisco.

Brockwell, P. J., \& Davis, R. A. (1996). Introduction to Time Series and Forecasting. New York: Springer. http://dx.doi.org/10.1007/978-1-4757-2526-1

Brockwell, P. J., \& Davis, R. A. (2002). Introduction to Time Series and Forecasting (2nd ed.). Springer. http://dx.doi.org/10.1007/b97391

Caporale, G. M., \& Gil-Alana, L. A. (2011). Multi-factor Gegenbauer processes and European inflation rates. Journal of Economic Integration, 26(2), 386-409. http://dx.doi.org/10.11130/jei.2011.26.2.386

Cheung, Y. W. (1993). Long memory in foreign-exchange rates. Journal of Business and Economic Statistics, 11(1), 93-101. http://dx.doi.org/10.1016/0261-5606(95)93616-U

Cheung, Y. W., \& Lai, K. (1995). A search of long memory in international stock market returns. Journal of International Money and Finance, 14, 597-615. http://dx.doi.org/10.1002/for.3980130205

Delgado, M., \& Robinson, P. (1994). New methods for the analysis of long memory time series: Application to Spanish inflation. Journal of Forecasting, 13, 97-107.

Dickey, D., \& Fuller, W. (1979). Distribution of the estimators for autoregressive time series with unit root. Journal of the American Statistical Association, 74, 427-431.

Diongue, A. K., \& Guegan, D. (2008). Estimation of k-factor GIGARCH process: A Monte Carlo study. 
Communications in Statistics-Simulation and Computation, 37, 2037-2049. http://dx.doi.org/10.1080/03610910802304994

Ferrara, L., \& Guegan, D. (1999). Estimation and applications of Gegenbauer processes. Technical Report 9927, CREST-INSEE.

Gray, H. L., Zhang, N. F., \& Woodward, W. A. (1989). On generalized fractional processes. Journal of Time Series Analysis, 10(233-257). http://dx.doi.org/10.1111/j.1467-9892.1989.tb00026.x

Hasser. (1993). Regression of spectral estimators with fractionally integrated time series. Journal of Time Series Analysis, 14, 369-380. http://dx.doi.org/10.1111/j.1467-9892.1993.tb00151.x

Hassler, U., \& Wolters, J. (1995). Long memory in inflation rates. international evidence. Journal of Business and Economic Statistics, 13, 37-45.

Hurst, H. E. (1951). Long-term storage capacity of reservoirs. Transactions of the American Society of Civil Engineers, 116, 770-799.

Hylleberg, S., Engle, R., Granger, C., \& Yoo, B. (1990). Seasonal integration and cointegration. Journal of Econometrics, 44, 215-238. http://dx.doi.org/10.1016/0304-4076(90)90080-D

Hyndman, \& Khandakar. (2008). Automatic time series forecasting: the forecast package for. Journal of Statistical Software, 27, 1-22.

Junttila, J. (2001). Structural breaks, ARIMA model and Finnish inflation forecasts. International Journal of Forecasting, 17, 203-230. http://dx.doi.org/10.1016/S0169-2070(00)00080-7

Kwiatkowski, D., Phillips, P. C. B., Schmidt, P., \& Shin, Y. (1992). Testing the null hypothesis of stationarity against the alternative of a unit root. Journal of Econometrics, 54, 159-178. http://dx.doi.org/10.1016/0304-4076(92)90104-Y

Noakes, D. J., Hipel, K. W., McLeod, A. I., Jimenez, C., \& Yakowitz, S. (1998). Forecasting annual geophysical time series. International Journal of Forecasting, 4.

Ooms, M., \& Franses, P. H. (1998). A seasonal periodic long memory model for monthly river flows. Technical report, Econometric Institute, Erasmus University Rotterdam.

Pincheira, P., \& Medel, C. A. (2012). Forecasting inflation with a simple and accurate benchmark: A crosscountry analysis. Working Papers 677, Central Bank of Chile.

Pufnik, \& Kunovac. (2006). Short-term forecasting of inflation in Croatia with seasonal ARIMA processes. Working Paper W-16, Croatia National Bank.

Sutcliffe, A. (1994). Time series forecasting using fractional differencing. Journal of Forecasting, 13, 383-393. http://dx.doi.org/10.1002/for.3980130404

Taqqu, M. S., Willinger, W., \& Sherman, R. (1997). Proof of a fundamental result in self-similar traffic modeling. Computer Communication Review, 27(5-23). http://dx.doi.org/10.1145/263876.263879

Velasco, C. (1999). Gaussian semi-parametric estimation of non-stationary time series. Journal of Time Series Analysis, 20(1), 87-127. http://dx.doi.org/10.1111/1467-9892.00127

Willinger, W., Taqqu, M. S., \& Teverovsky, V. (1999). Stock market prices and long range dependence. Finance and Stochastics, 3, 1-13. http://dx.doi.org/10.1007/s007800050049

Woodward, W. A., Gray, H. L., \& Elliott, A. C. (2011). Applied Time Series Analysis. Statistics: A series of Textbooks and Monographs. CRC Press.

\section{Appendix A}

Softwares Used in the Study.

Matlab, R software, Stata, Spss, Gretl.

\section{Copyrights}

Copyright for this article is retained by the author(s), with first publication rights granted to the journal.

This is an open-access article distributed under the terms and conditions of the Creative Commons Attribution license (http://creativecommons.org/licenses/by/3.0/). 